\title{
Fundamental Physical Constants 1986 Adjustments
}

\author{
E. Richard Cohen, Thousand Oaks CA and \\ Barry N. Taylor, Gaithersburg
}

(Rockwell International Science Center and National Bureau of Standards)

Over the past twenty years a surprisingly strong link has developed between the applied science of metrology and atomic, molecular and solid state physics. The techniques of frequency multiplication, and the precise measurement of frequency at infrared and visible wavelengths, have reached such a level of development that the metre has been redefined in terms of the distance travelled by light in a given time ${ }^{1,2}$ ). The direct linking of atomic lattice spacings to optical wavelengths has produced a significant improvement in the determination of the Avogadro constant ${ }^{3,4}$ ). Impressive progress has been made in the precision of measurement of the electron anomalous magnetic moment ${ }^{5}$ ) as well as the numerical evaluation of the associated sixth- and eighth-order Feynman diagrams ${ }^{6}$ ). The most striking metrological advance occurred when $\mathrm{K}$. von Klitzing in 1980 observed the quantization of electrical conductance ${ }^{7}$ ) and achieved not only a direct macroscopic measurement of the fine-structure constant, but the 1985 Nobel Prize in Physics as well ${ }^{8}$ ).

The CODATA Task Group on Fundamental Constants has recently completed a new evaluation of the fundamental physical constants ${ }^{9}$ ) taking into account the truly extraordinary amount of experimental and theoretical work that has become available since the previous adjustment in $1973^{10}$ ).

Because of past problems associated with the statistical treatment of such a diverse set of experimental and theoretical data, increased attention was directed in the 1986 analysis to questions of statistical validity. The least-squares approach to the analysis of such data has been described in detail in previous reviews $11,12,13$, but in brief, each experimental result with its estimated uncertainty represents a constraint on the values of a set of physical quantities, expressed as an algebraic relationship involving the auxiliary constants, the unknown stochastic data and their unknown experimental and theoretical errors. The least-squares solution determines the "best" values of these unknown quantities by finding the

Table 1. 1986 Adjustment of the fundamental constants.

Comparison of the initial and final stages of the multivariate analysis.

\begin{tabular}{ccl}
\hline \hline & $\begin{array}{c}\text { Initial } \\
\text { (least-squares, } \\
\text { external error) }\end{array}$ & $\begin{array}{l}\text { Final } \\
\text { (extended } \\
\text { least-squares) }\end{array}$ \\
$N$ & 35 & 22 \\
$\nu$ & 30 & 17 \\
$\chi^{2}$ & 106.6 & 17.01 \\
$R_{\mathrm{B}}$ & 1.89 & 1.00 \\
\hline$\alpha^{-1}$ & $137.035996(11)$ & $137.0359895(61)$ \\
$K_{\mathrm{V}}$ & $1-7.24(54) \times 10^{-6}$ & $1-7.59(30) \times 10^{-6}$ \\
$K_{\Omega}$ & $1-1.524(92) \times 10^{-6}$ & $1-1.563(50) \times 10^{-6}$ \\
$d_{220}$ & $192.015553(74) \mathrm{pm}$ & $192.015540(40) \mathrm{pm}$ \\
$\mu_{\mu} / \mu_{\mathrm{p}}$ & $3.18334571(87)$ & $3.18334547(47)$ \\
\hline
\end{tabular}

weighted mean of the observational equations that gives the smallest statistical variances consistent with the constraints.

The weight $\omega_{i}$ associated with each experimental datum is the reciprocal of the variance, or statistical mean square error, $\sigma_{i}^{2}$ which is however only available as an a priori estimate $s_{i}^{2}$ and is itself uncertain. The usual least-squares procedure multiplies the calculated uncertainties of an adjustment by the Birge ratio, $R_{\mathrm{B}}=\left(\chi^{2} / v\right)^{1 / 2}$, to rescale the weights and give a value of $\chi^{2}$ equal to its expectation value $v$. This is equivalent to an a posteriori evaluation of the 'error associated with unit weight' and is valid if the assigned uncertainties have only relative significance, or if the systematic errors of all input data are roughly similar. However, when the data come from different and unrelated sources with broadly different physical content, a uniform expansion of all uncertainties can hardly be justified. In such a case, any rescaling of the assigned weights should consider all other information that may be available concerning the uncertainty assignment of each individual datum. In analyzing the 1986 input data we have considered not only the usual least-squares algorithm, but also the algorithm proposed by Tuninskii and Kholin in $1975^{14}$ ) of the Mendeleyev Institute of Metrology in Leningrad, as well as a modification of it suggested by Taylor in $1982^{15}$ ), and the extended least-squares algorithms described by Cohen in $\left.1976^{16}\right), 1978^{17}$ ) and 1980
${ }^{18)}$. These algorithms use the consistency of the data to provide additional information with which to improve these $a$ priori estimates of the variances.

\section{Input Data}

As in previous adjustments, the data are divided into two categories:

a) the more precise data (auxiliary constants) that are not subject to adjustment because of their relatively low uncertainties, and

b) the less precise or stochastic data that are subject to adjustment.

There is no formal basis for separation into these two categories except that a variable with an uncertainty much smaller than that of other variables to which it is connected will be only slightly altered by the adjustment and can hence be treated as a constant. The uncertainty of an auxiliary constant is typically one twentieth the uncertainty of the stochastic datum with which it appears. All the auxiliary constants have uncertainties not greater than $0.02 \mathrm{ppm}$ while the 38 items of stochastic data have uncertainties in the range 0.05 ppm to $10 \mathrm{ppm}$

On the basis of a preliminary screening, three of the 38 items were identified as inappropriate for further consideration in the adjustment: one because it represented an uncompleted measurement; a second because it had recently been shown to be in error; and the third because it required for its interpretation an inadequately developed theoretical expression. The remaining 35 items for- 
med the basis for an analysis with five unknowns. These unknowns were the inverse fine-structure constant $\alpha^{-1}$, the ratio of the standard volt (defined and maintained by the Josephson effect) to the SI volt $K_{\mathrm{v}}$, the ratio of the standard ohm (maintained in terms of a set of standard resistance coils, corrected for drift to the value on 1 Jan, 1985) to the SI ohm $K_{\Omega}$, the lattice spacing of the silicon lattice (at $22.5^{\circ} \mathrm{C}$ in vacuum) $d_{220}$, and the ratio of the muon magnetic moment to the proton magnetic moment, $\mu_{\mu} / \mu_{\mathrm{p}}$. The multivariate analysis was carried out using the several algorithms mentioned above; the details are given in CODATA Bulletin No. $63^{9}$ ).

From the results of applying the various algorithms to the data and from a consideration of the effects on consistency produced by eliminating data, we deleted 11 observations of very low weight and two other older observations which were of low weight and somewhat discrepant relative to their claimed precision. As a result, 22 items of stochastic data remained to define the data set for the 1986 recommended values of the fundamental physical constants. This final solution is compared with the initial adjustment with 35 observations in Table 1. The uncertainties given for the initial adjustment (with $\chi^{2}=106.6$ and $R_{\mathrm{B}}=1.89$ ) are computed from external consistency. These uncertainties, which are expanded by the factor $R_{\mathrm{B}}$ from the internally computed values, are still significantly smaller than the corresponding uncertainties of the 1973 adjustment. Even though this solution contains some discordant data, none of these quantities differs from its final recommended value by more than 0.7 standard deviations of that difference, and only $K_{\mathrm{V}}$ differs from the final recommended value by more than one standard deviation of that value.

Table 2 gives a selected list of values of the fundamental constants of physics and chemistry; Table 3 presents a set of related values, such as the quantities $V_{\mathrm{BI}-76}, \Omega_{\mathrm{BI} 85}$ and $d_{220}$ that are a necessary part of the data of the adjustment, but cannot be considered as fundamental in the same sense as the quantities of Table 2.

\section{Comparisons and Discussion}

The precision of the 1986 recommended values is roughly an order of magnitude better than that of their 1973 counterparts; the precision of the Rydberg constant $R_{\infty}$ is improved by a factor of 60 while that of $m_{\mathrm{p}} / m_{\mathrm{e}}$ and $\alpha$, by factors of approximately 20 . The most significant revision is the change in $K_{\mathrm{V}}$ and the resultant $7.75 \mathrm{ppm}$ change

Table 2. Summary of the 1986 recommended values of the fundamental physical constants.

A list of some fundamental constants of physics and chemistry based on a least-squares adjustment with 17 degrees of freedom. The digits in parentheses are the one-standarddeviation uncertainty in the last digits of the given value. Since the uncertainties of many of these entries are correlated, the full covariance matrix must be used in evaluating the uncertainties of quantities computed from them.

\begin{tabular}{lllll}
\hline \hline Quantity & Symbol & Value & Units & $\begin{array}{c}\text { Relative } \\
\text { uncertainty } \\
(\text { ppm) }\end{array}$ \\
\hline
\end{tabular}

speed of light in vacuum permeability of vacuum

permittivity of vacuum

Newtonian constant of gravitation Planck constant $h / 2 \pi$

elementary charge

magnetic flux quantum, $h / 2 e$

Josephson frequency-voltage ratio quantized Hall resistance, $h / e^{2}=\mu_{0} c / 2 \alpha$

electron mass

in electron volts, $m_{e} c^{2} /\{e\}$ electron specific charge muon mass

in electron volts, $m_{\mu} c^{2} /\{e\}$ muon-electron mass ratio proton mass

in electron volts, $m_{\mathrm{p}} c^{2} /\{e\}$ proton-electron mass ratio neutron mass

in electron volts, $m_{\mathrm{n}} c^{2} /\{e\}$ neutron-electron mass ratio neutron-proton mass ratio

fine-structure constant, $\mu_{0} c e^{2} / 2 h$

inverse fine-structure constant Rydberg constant, $m_{\mathrm{e}} c \alpha^{2} / 2 h$

Bohr radius, $\alpha / 4 \pi R_{\infty}$

Compton wavelength, $h / m_{\mathrm{e}} c$ $\lambda_{\mathrm{C}} / 2 \pi=\alpha a_{\circ}=\alpha^{2} / 4 \pi R_{\infty}$ classical electron radius, $\alpha^{2} a$ 。 Thomson cross section, $(8 \pi / 3) r_{\mathrm{e}}^{2}$ Bohr magneton, $e h / 2 m_{\mathrm{e}}$ nuclear magneton, $e \hbar / 2 m_{\mathrm{p}}$ electron magnetic moment

in Bohr magnetons

in nuclear magnetons

proton magnetic moment

in Bohr magnetons

in nuclear magnetons

diamagnetic shielding correction

for protons in pure water,

spherical sample, $25^{\circ} \mathrm{C}, 1-\mu_{\mathrm{p}}^{\prime} / \mu_{\mathrm{p}}$ shielded proton moment $\left(\mathrm{H}_{2} \mathrm{O}\right.$, sph., $\left.25^{\circ} \mathrm{C}\right)$

in Bohr magnetons

in nuclear magnetons proton gyromagnetic ratio

uncorrected $\left(\mathrm{H}_{2} \mathrm{O}\right.$, sph., $\left.25^{\circ} \mathrm{C}\right)$

muon-proton

magnetic moment ratio neutron magnetic moment

in Bohr magnetons

in nuclear magnetons

$\begin{array}{ll}c & 299792458 \\ \mu_{\circ} & 4 \pi \times 10^{-7} \\ & =12.566370614 \ldots \\ \epsilon_{\circ} & 1 / \mu_{\circ} c^{2} \\ & =8.854187817 \ldots \\ G & 6.67259(85) \\ h & 6.6260755(40) \\ \hbar & 1.05457266(63) \\ e & 1.60217733(49) \\ \Phi_{\circ} & 2.06783461(61) \\ 2 e / h & 4.8359767(14) \\ R_{\mathrm{H}} & 25812.8056(12) \\ & \\ m_{\mathrm{e}} & 9.1093897(54)\end{array}$

$m$

$m_{\mathrm{e}} \quad 9.1093897(54)$

$5.48579903(13)$

$0.51099906(15)$

$-e / m_{\mathrm{e}} \quad-1.75881962(53)$

$m_{\mu} \quad 1.8835327(11)$

$0.113428913(17)$

$105.658389(34)$

$m_{\mu} / m_{e} \quad 206.768262(30)$

$\begin{array}{ll}m_{\mathrm{p}} & 1.6726231(10)\end{array}$

$1.007276470(12)$ $938.27231(28)$

$m_{\mathrm{p}} / m_{\mathrm{e}} \quad 1836.152701(37)$

$m_{\mathrm{n}} \quad 1.6749286(10)$

$1.008664904(14)$

$939.56563(28)$

$m_{\mathrm{n}} / m_{\mathrm{e}} \quad 1838.683662(40)$

$m_{\mathrm{n}} / m_{\mathrm{p}} \quad 1.001378404(9)$

$\alpha \quad 7.29735308(33)$

$\alpha^{-1} \quad 137.0359895(61)$

$R_{\infty} \quad 10973731.534(13)$

$a_{\circ} \quad 0.529177249(24)$

$\lambda_{\mathrm{C}} \quad 2.42631058(22)$

$\lambda_{\mathrm{C}} \quad 3.86159323(35)$

$r_{\mathrm{e}} \quad 2.81794092(38)$

$\sigma_{\mathrm{e}} \quad 0.66524616(18)$

$\mu_{\mathrm{B}} \quad 927.40154(31)$

$\mu_{\mathrm{N}} \quad 0.50507866(17)$

$\mu_{\mathrm{e}} \quad 928.47701(31)$

$\mu_{\mathrm{e}} / \mu_{\mathrm{B}} \quad 1.001159652193(10)$

$\mu_{\mathrm{e}} / \mu_{\mathrm{N}} \quad 1838.282000(37)$

$\mu_{\mathrm{p}} \quad 1.41060761(47)$

$\mu_{\mathrm{p}} / \mu_{\mathrm{B}} \quad 1.521032202(15)$

$\mu_{\mathrm{p}} / \mu_{\mathrm{N}} \quad 2.792847386(63)$

\begin{tabular}{|c|c|}
\hline $\begin{array}{l}\mathrm{ms}^{-1} \\
\mathrm{NA}^{-2} \\
10^{-7} \mathrm{NA}^{-2}\end{array}$ & (exact) \\
\hline $\begin{array}{l}10^{-12} \mathrm{~F} \mathrm{~m}^{-1} \\
10^{-11} \mathrm{~m}^{3} \mathrm{~kg}^{-1} \mathrm{~s}^{-2} \\
10^{-34} \mathrm{~J} \mathrm{~s}^{-34} \\
10^{-34} \mathrm{~J} \mathrm{~s} \\
10^{-19} \mathrm{C} \\
10^{-15} \mathrm{~Wb} \\
10^{14} \mathrm{~Hz} \mathrm{~V}^{-1} \\
\Omega\end{array}$ & $\begin{array}{l}\text { (exact) } \\
128 \\
0.60 \\
0.60 \\
0.30 \\
0.30 \\
0.30 \\
0.045\end{array}$ \\
\hline $\begin{array}{l}10^{-31} \mathrm{~kg} \\
10^{-4} \mathrm{u} \\
\mathrm{MeV} \\
10^{11} \mathrm{C} \mathrm{kg}^{-1} \\
10^{-28} \mathrm{~kg} \\
\mathrm{u} \\
\mathrm{MeV}\end{array}$ & $\begin{array}{l}0.59 \\
0.023 \\
0.30 \\
0.30 \\
0.61 \\
0.15 \\
0.32 \\
0.15\end{array}$ \\
\hline $\begin{array}{l}10^{-27} \mathrm{~kg} \\
\mathrm{u} \\
\mathrm{MeV}\end{array}$ & $\begin{array}{l}0.59 \\
0.012 \\
0.30 \\
0.020\end{array}$ \\
\hline $\begin{array}{l}10^{-27} \mathrm{~kg} \\
\mathrm{u} \\
\mathrm{MeV}\end{array}$ & $\begin{array}{l}0.59 \\
0.014 \\
0.30 \\
0.022 \\
0.009\end{array}$ \\
\hline $\begin{array}{l}\mathrm{m}^{-1} \\
10^{-10} \mathrm{~m} \\
10^{-12} \mathrm{~m} \\
10^{-13} \mathrm{~m} \\
10^{-15} \mathrm{~m} \\
10^{-28} \mathrm{~m}^{2}\end{array}$ & $\begin{array}{l}0.045 \\
0.045 \\
0.0012 \\
0.045 \\
0.089 \\
0.089 \\
0.13 \\
0.27\end{array}$ \\
\hline $\begin{array}{l}10^{-26} \mathrm{~J} \mathrm{~T}^{-1} \\
10^{-26} \mathrm{~J} \mathrm{~T}^{-1} \\
10^{-26} \mathrm{~J} \mathrm{~T}^{-1}\end{array}$ & $\begin{array}{l}0.34 \\
0.34 \\
0.34 \\
1 \times 10^{-5} \\
0.020\end{array}$ \\
\hline $\begin{array}{l}10^{-26} \mathrm{~J} \mathrm{~T}^{-1} \\
10^{-3}\end{array}$ & $\begin{array}{l}0.34 \\
0.010 \\
0.023\end{array}$ \\
\hline
\end{tabular}

$25.689(15)$

$\mu_{\mathrm{p}}^{\prime} \quad 1.41057138(47)$

$\mu_{\mathrm{p}}^{\prime} / \mu_{\mathrm{B}} \quad 1.520993129(17)$

$\mu_{\mathrm{p}}^{\prime} / \mu_{\mathrm{N}} \quad 2.792775642(64)$

$\gamma_{\mathrm{p}} \quad 26752.2128(81)$

$\gamma_{\mathrm{p}} / 2 \pi \quad 42.577469(13)$

$\gamma_{p}^{\prime} \quad 26751.5255(81)$

$42.576375(13)$

$$
\begin{aligned}
& 10^{-6} \\
& 10^{-26} \mathrm{~J} \mathrm{~T}^{-1}
\end{aligned}
$$

$10^{-3}$

0.30

$\begin{array}{ll}\mathrm{MHz} \mathrm{T}^{-1} & 0.30 \\ 10^{4} \mathrm{~s}^{-1} \mathrm{~T}^{-1} & 0.30\end{array}$

$\mathrm{MHz} \mathrm{T}^{-1} \quad 0.30$

$\mu_{\mu} / \mu_{\mathrm{p}} \quad 3.18334547(47)$

$\mu_{\mathrm{n}} \quad 0.96623707(40)$

$\mu_{\mathrm{n}} / \mu_{\mathrm{B}} \quad 0.00104187563(25)$

$\mu_{\mathrm{n}} / \mu_{\mathrm{N}} \quad 1.91304275(45)$ 
Table 2. Summary of the 1986 recommended values of the fundamental physical constants (continued).

\begin{tabular}{lcccc}
\hline \hline Quantity & Symbol & Value & Units & $\begin{array}{c}\text { Relative } \\
\text { uncertainty } \\
(\mathrm{ppm})\end{array}$ \\
\hline
\end{tabular}

neutron-electron magnetic moment ratio

neutron-proton

magnetic moment ratio

\section{Avogadro constant}

Faraday constant, $N_{\mathrm{A}} e$

electron molar mass

muon molar mass

proton molar mass

Hartree energy, $e^{2} / 4 \pi \epsilon_{0} a_{\circ}=2 R_{\infty} h c$

in $\mathrm{eV}, E_{\mathrm{h}} /\{e\}$

molar gas constant

Boltzmann constant, $R / N_{\mathrm{A}}$

first radiation constant, $2 \pi h c^{2}$

second radiation constant, $h c / k$

Wien displacement law constant, $\left(\pi^{2} / 60\right) k^{4} / \hbar^{3} c^{2}$ $b=\lambda_{\max } T=c_{2} / 4.96511423 \ldots$

Stefan-Boltzmann constant,

$\begin{array}{cl}\mu_{\mathrm{n}} / \mu_{\mathrm{e}} & 0.00104066882(25) \\ \mu_{\mathrm{n}} / \mu_{\mathrm{p}} & 0.68497934(16) \\ N_{\mathrm{A}}, L & 6.0221367(36) \\ F & 96485.309(29) \\ M(\mathrm{e}), M_{\mathrm{e}} & 5.48579903(13) \\ M(\mu), M_{\mu} & 1.13428913(17) \\ M(\mathrm{p}), M_{\mathrm{p}} & 1.007276470(12) \\ E_{\mathrm{h}} & 4.3597482(26) \\ & 27.2113961(81) \\ R & 8.314510(70) \\ k & 1.380658(12) \\ c_{1} & 3.7417749(22) \\ c_{2} & 0.01438769(12) \\ b & 2.897756(24) \\ \sigma & 5.67051(19)\end{array}$

0.24

$10^{23} \mathrm{~mol}^{-1}$

$\mathrm{C} \mathrm{mol}^{-1}$

$10^{-7} \mathrm{~kg} / \mathrm{mol}$

$10^{-4} \mathrm{~kg} / \mathrm{mol}$

$10^{-3} \mathrm{~kg} / \mathrm{mol}$

$10^{-18} \mathrm{~J}$

$\mathrm{eV}$

$\mathrm{J} \mathrm{mol}^{-1} \mathrm{~K}^{-1}$

$10^{-23} \mathrm{~J} \mathrm{~K}^{-1}$

$10^{-16} \mathrm{~W} \mathrm{~m}^{2}$

$\mathrm{m} \mathrm{K}$

$10^{-3} \mathrm{~m} \mathrm{~K}$

$10^{-8} \mathrm{~W} \mathrm{~m}^{-2} \mathrm{~K}^{-4} \quad 34$ in the recommended value of $2 e / h$ : the 1986 value is higher than the 1973 value by three times the standard deviation of the latter. The Josephson frequency-voltage ratio $(483594.0 \mathrm{GHz} / \mathrm{V})$ adopted by the Consultative Committee on Electricity in 1972, which was intended to reproduce the SI value and which forms the basis of the legal representation of the volt in many countries, is too small by about $8 \mathrm{ppm}$. This unsatisfactory situation is undergoing international review and will be rectified in the near future ${ }^{19,20}$ ).

Since the fine-structure constant $\alpha$, which is proportional to $e(e / h)$, has changed by only $0.37 \mathrm{ppm}$, the increase in $2 e / h$ is strongly correlated to an approximately equal fractional decrease in $e$. If $e^{2} / h$ is almost unchanged and $e$ decreases, the fractional decrease in $h$ must be twice as great. Furthermore, the quantity $N_{\mathrm{A}} h$ is proportional to $\alpha^{2}$; a decrease in $h$ is coupled with an increase in $N_{\mathrm{A}}$ and with an increase (approximately half as large) in $F$. The changes from the 1973 values of many quantities are thus strongly correlated, and all of the large changes can be directly linked to the change in $K_{\mathrm{v}}$. This is seen in the comparison of the 1973 and 1986 recommended values of several constants shown in Table 4.

A major part of the difference between 1973 and 1986 may be traced to the deletion, in 1973, of two Faraday determinations which seemed to be discrepant with the remaining data. In hindsight this 'discrepancy' was not that severe. Adjustment No. 40 in that analysis $\left.{ }^{13}\right)$, which differs from the 1973 recommended set (No. 41) only in its retention of the two Faraday determinations, gives a value for $2 e / h$ that is $5.3 \mathrm{ppm}$ higher than the 1973 recommendation and only $2.5 \pm 2.0 \mathrm{ppm}$ lower than the present value. It is important to recognize, however, that there are no similar data discrepancies in the present analysis; the deleted data have been either extremely discrepant or of very low weight (or both). Thus, it is improbable that any future reassessment of the current data could change the recommendations of the present analysis by as much as two standard deviations.

The 1986 analysis does not separately consider those data that are independent of quantum electrodynamics (WOED data), as was done in 1969 and 1973. If the measurements that depend on QED information (the electron anomalous moment and the muonium hyperfine-structure) are deleted, the remaining 20 items give $\alpha^{-1}=$ $137.0359846(94)$. This differs from the

The lattice spacing of single-crystal Si can vary by parts in $10^{7}$ depending on the preparation process. Measurements at PTB indicate also the possibility of distortions from exact cubic symmetry of the order of $0.2 \mathrm{ppm}$. 
Table 4. Comparison of 1973 and 1986 adjustments

\begin{tabular}{cccc}
\hline & $\begin{array}{c}\text { change from } \\
1973 \\
\text { quantity }\end{array}$ & $\begin{array}{c}\text { uncertainties } \\
\text { recommended } \\
\text { value } \\
\text { (ppm) }\end{array}$ & \multicolumn{2}{c}{$\begin{array}{c}\text { recommended } \\
\text { values } \\
\text { (ppm) }\end{array}$} \\
\hline$\alpha^{-1}$ & -0.37 & 1973 & 1986 \\
$e$ & -7.4 & 2.9 & 0.30 \\
$h$ & -15.2 & 5.4 & 0.60 \\
$m_{\mathrm{e}}$ & -15.8 & 5.1 & 0.59 \\
$N_{\mathrm{A}}$ & +15.2 & 5.1 & 0.59 \\
$m_{\mathrm{p}} / m_{\mathrm{e}}$ & +0.64 & 0.38 & 0.020 \\
$F$ & +7.8 & 2.8 & 0.30 \\
$2 e / h$ & +7.8 & 2.6 & 0.30 \\
\hline
\end{tabular}

recommended value by $0.036 \pm 0.059$ $\mathrm{ppm}$. The WQED value of $K_{\mathrm{V}}$ differs from the recommended value by $0.01 \pm 1.03$ ppm. There is clearly no basis for any distinction between QED and WOED data.

By deleting the quantum Hall effect (QHE) data from the analysis one may investigate the validity of the theoretical relation $R_{\mathrm{H}}=h / e^{2}$. If the QHE data are deleted, the value of $\alpha^{-1}$ becomes 137.0359884(79); the difference from the recommended value is $-0.009 \pm$ $0.071 \mathrm{ppm}$. A value of $\alpha^{-1}$ from the Hall resistance data and the direct ohm determinations yields $137.0359943(127)$. This differs by only $0.043 \pm 0.085 \mathrm{ppm}$ from the value above. Thus, based on the presently available observational data, there is no evidence of any discrepancy in the QHE theory at the current levels of precision.

\section{REFERENCES}

1. Comptes Rendus des Séances de la $17^{\circ}$ CGPM (BIPM, Sèvres, France) 1983.

2. Hudson R.P. (editor), Metrologia 19 (1984) 163.

3. Deslattes R.D. et al., Phys. Rev. Lett. 33 (1974) 463 .

4. Seyfried P. et al., in Precision Measurement and Fundamental Constants II, eds. B.N. Taylor and W.D. Phillips, Natl. Bur. Stand. (US), Spec. Publ. 617 (U.S. Govt. Printing Office, Washington, DC) 1984, p. 313. 5. Van Dyck R.S. jr, Schwinberg P.B. and Dehmelt H.G., in Atomic Physics - 9, eds. R.S. van Dyck jr and E.N. Fortson (World Scientific Publishing Co., Singapore) p. 38. 6. Kinoshita T. and Sapirstein J., Op. Cit., p. 38.

7. Von Klitzing K., Dorda G. and Pepper M., Phys. Rev. Lett. 45 (1980) 494.

8. Imry Y., 'Klaus von Klitzing', Europhys. News, 16 (1985) 11/12.

9. Cohen E.R. and Taylor B.N., 'The 1986 Adjustment of the Fundamental Physical Constants', CODATA Bulletin No. 63 (International Council of Scientific Unions - Committee on Data for Science and Technology (CODATA), 51, Blvd de Montmorency, 75016 Paris, France) Nov. 1986.

10. "Recommended Consistent Values of the Fundamental Physical Constants, 1973", CODATA Bulletin No. 11 (ICSU, Paris) 1973.
11. Cohen E.R., Crowe K.M. and Du Mond J.W.M., Fundamental Constants of Physics (Interscience Publishers, New York) 1957. 12. Taylor B.N., Parker W.H. and Langenberg D.N., Rev. Mod. Phys. 41 (1969) 375; also published as The Fundamental Constants and Quantum Electrodynamics (Academic Press, New York).

13. Cohen E.R. and Taylor B.N., J. Phys. Chem. Ref. Data 2 (1973) 663.

14. Tuninskii V.S. and Kholin S.V., "Concerning changes in the methods for adjusting the physical constants", Internal Report, Mendeleyev Research Institute of Metrology (VNIIM), Leningrad; Metrologiya 8 (1975) 3 [in Russian].

15. Taylor B.N., "Numerical comparisons of several algorithms for treating inconsistent data in a least-squares adjustment of the fundamental constants", Natl. Bur. Stand. Report NBSIR 81-2426 (Jan. 1982).

16. Cohen E.R., "Extended' least squares", Report SCTR-76-1 (Rockwell International Science Center) Jan. 1976.

17. Cohen E.R., "An extended least-squares algorithm for treating inconsistent data", Report SCTR-78-11 (Rockwell International Science Center); see also ref. 4, p. 391.

18. Cohen E.R., in "Metrology and Fundamental Constants", Proceedings of the International School of Physics 'Enrico Fermi', Course LXVIII, eds. A. Ferro-Milone, P. Giacomo and S. Leschiutta (North Holland, Amsterdam) 1980, p. 581.

19. Taylor B.N., J. Res. Natl. Bur. Stand. 91 (1986) 299.

20. Taylor B.N., J. Res. Natl. Bur. Stand. 92 (1987) 55.

\section{International Cooperation Strengthens European Optics}

Two events, of considerable importance to the future of optical technology in Europe, marked the opening of the recent Fourth International Symposium on Optical and Optoelectronic Applied Science and Engineering, arranged by SPIE/ ANRT at the Hague in the Netherlands. These were the creation of a new association of West European Optical Societies called EUROPTICA, and the declaration of a Memorandum of Understanding (MOU) between EUROPTICA, EPS (European Physical Society) and SPIE - The International Society for Optical Engineering based in the USA.

In recent years, as the pace of developments in optical science and engineering has increased, and more European countries have formed their own Optical Societies, and also as a result of the now established trend, led by SPIE, for the organization of large multidisciplinary conferences, the need has arisen for the creation of a focal point through which future major international events could be channelled. As a start, the partners of the MOU have agreed to collaborate in the organization of one major meeting in Europe each year to be known as the International Conference on Optical Science and Engineering. This title has been chosen to reflect the interests of EPS in optical science, those of EUROPTICA in the industrial application of new developments in optics technology and the professional interests of optical engineers through their membership of SPIE. Plans are already well advanced for the first such meeting to be held from 19-23 September 1988 at the Hamburg Conference Centre (CCH). The second meeting will be in Paris from 24-28 April 1989 at the Palais des Congrès de la Porte Maillot.

This new partnership of non-profit bodies representing the interests of over 20,000 scientists, engineers and technologists in optics is expected to develop, in the course of time, to encompass other services to the optical community in the fields of education, exhibitions and publishing. The partnership will have the additional benefit of speeding up the transfer of technology into industry and helping to promote international trade. These activities will be managed by an appointed Joint Policy Committee (JPC) with the following representation:

EPS - European Physical

Society

H.A. Ferweda,

Universiteit Groningen

G. Thomas, EPS,

Secretary of JPC

H. Tiziani, Universität

Stuttgart, Institut für

Technische Optik,

Vice-chairman of JPC
EUROPTICA including Europtica Services

P. Bosec, ESSILOR

H. Walter, Director

Research and Development,

Rodenstock

P. Zaleski, Director, ANRT

For further information contact: Dr. L.R. Baker

Sira Ltd., South Hill, Chislehurst

Kent BR7 5EH, UK

Tel. : (1) 4672636

Telex: 896649

SPIE - The International Society of Optical Engineering

L.R. Baker, Technical Director (Optics), Sira Ltd. Chairman of JPC

B.J. Thompson, Provost, University of Rochester

W.L. Wolfe,

University of Arizona,

Optical Science Center 